\title{
Rosencrantz and Guildenstern are 'dead'?
}

\author{
John F Catherwood The Queen's University, Belfast
}

\begin{abstract}
Author's abstract
The article recently published in this journal by $\operatorname{Dr} B A$ Rix, a member of the Danish Council of Ethics (DCE), was heavily criticised by Dr David Lamb and Mr Christopher Pallis in subsequent commentaries. The editorial column by Professor Raanan Gillon also criticised the position put forward by Rix. In this article I contend that the definition of death put forward by Pallis and Lamb suffers certain philosophical shortcomings, that the position put forward by Rix deserves fuller consideration, and that Rix is not to be dismissed easily.
\end{abstract}

B A Rix, the secretary to the DCE, recently contributed an article to this journal (1). It seems strange to me that the main point of philosophical criticism, raised by Lamb and Pallis, was that a definition of death based solely on the status of an individual heart can lead one into absurd difficulties (2). The phrase which Pallis and Lamb so rightly criticise, is 'the criterion of death should still be the cessation of cardiac activity'. However, while this claim occurs in the author's abstract and the introductory paragraph, it is not supported in the rest of the article. It is in fact contradicted by the more detailed arguments Rix puts forward in the rest of the text. I can sympathise with Pallis, when he records a profound weariness and sense of déjà vu: the old, old, arguments Pallis resurrects have the same effect on me. Yet on reading Rix I find that there is a new, and different, challenge; one which those old arguments do little to answer.

It is undoubtedly true that we need a means of telling when a human being is dead. Human beings have a special moral status, they are part of a network of personal relationships, and they are also given a legal status. At the point of death their moral status changes, their friends and relatives will be affected as the relationship changes, and the laws regarding inheritance, taxation and murder, may be brought to bear. With the change in moral status of the now dead human being, the duties of attending medical staff will change. It is for these reasons that we need a set of clear

\section{Key words}

Death; brainstem death; organ trnsplants. 'indicators', or criteria, for death. The current set of 'indicators' used in the UK are irreversible unconsciousness, and irreversible apnoea. Both these conditions are brought about by the cessation of brainstem function (3). If these indicators of death are accepted, and it must be remembered that they are accepted neither by many religious bodies, nor by some doctors (4), then a human being who enters this physiological state can be declared dead. It should be noted that in some ways the demand for apnoea is a reiteration of the importance of brainstem function. Irreversible apnoea must be a result of damage to the brainstem, not a result of damage to the lungs or the torso.

\section{'Concept' and 'criteria' - can they be distinguished?}

Proponents of the claim 'brainstem death is death' often find that it is not accepted as the definition of death. I believe that an important reason for their failure to gain acceptance, is that the claim they appear to make is too strong. Intentionally or not, they constantly seem to be claiming that this definition is the, one and only, definition of death. That Pallis and Lamb stipulate that a distinction must be drawn, between the concept of death and the criteria for death, does little to help them in these difficulties. They claim to define death as a concept, and then seek 'criteria' for the instantiation of that concept. 'Death is the loss of the capacity for consciousness and the capacity for spontaneous respiration' is Pallis's definition of the concept of death. He also claims that 'all death is, and always has been, brainstem death' (5). To make such a claim is to suggest that the many other uses of the word 'death' are either incorrect, inexact, or non-factual, metaphorical expressions. Yet the concept of death is not solely a biological one: death is not only a biological condition. It may be viewed as the cessation of experience, the departure of the soul from the body, or a passage into 'another mode of existence'. Every culture has a range of accounts of what death is.

Contrary to Pallis (5), 'the departure of the soul from the body' cannot be 'translated' as 'loss of the capacity for consciousness'. The departure of the soul may result in the loss of the capacity for consciousness, but here it must be remembered that the human being is 
dead because the soul has departed, not because the capacity for consciousness is lost. Other accounts may be formulated, in which the cessation of consciousness occurs before the soul departs: the two events are causally and conceptually distinct. 'Translating' in this case is better rendered as 're-defining', or 'reducing'. $\mathrm{He}$ is attempting to reduce a metaphysical account (or at least a non-empirical account) to an empirical account. Friedrich Waismann (6) claimed that this type of reduction is impossible. The concepts being used are of two distinct logical types, they come from different 'language strata'. There is no route by which the concepts of one 'language stratum' can be shown to be logically equivalent to concepts from a different stratum.

Moreover, claiming that the loss of the capacity for consciousness is equivalent to the permanent, irreversible, loss of cellular activity in the brainstem (or in any other part of the brain), is another obviously reductionist move. It requires either, the assumption that consciousness is cellular activity, or, the assumption that consciousness is inherent in the structure of the cells: both are materialist notions (7). Both are philosophically controversial positions: here again, Waismann's comments on 'language strata' apply. Alternatively, if Pallis does not wish to make that controversial reduction, it may be put forward as an empirical claim, that loss of the capacity for consciousness has always in the past coincided with the loss of function of a specific group of cells. As such it may be regarded as a contingent claim, an empirical hypothesis, but, in that case, it is not a 'definition' of loss of the capacity for consciousness, (nor is it a 'definition' of death), and it is not a proof of any causal connection between the two events. It is hard to believe that there is no causal connection, but we can only assume that there is a connection (2).

To say that 'death is brainstem death', in the belief that this will clear up any doubts about when we should declare a person dead, is also to ignore the nature of the type of definition being offered. It is a definition solely in biological terms: a definition of an empirical concept of death. Waismann (6) also noted that many empirical concepts, are, by nature, 'open textured'. By this he meant that their definition can never be exhausted. No matter how exhaustive the definition, there is still the possibility of adding more details, ad infinitum: the definition can never be complete. This is not to be confused with 'vagueness'; a concept is said to be 'vague' if it can be used in several different ways with different meanings or nuances of meaning. The empirical concept of death is vague in this sense, in that it can be defined in a multitude of ways, as a biological term. 'Death is brainstem death' and 'death is cessation of all heart, lung and brain function' are two definitions of the same empirical concept. Arguments as to which empirical definition should be the 'empirical definition' will reduce the vagueness of the term, leaving us with one definition. If the one we choose is 'brainstem death is death', or, if it is 'death is the cessation of all heart, lung, and brain function', the vagueness of this empirical concept will be equally reduced. It must, of course, be borne in mind that the 'open texture' of the empirical concept will always leave room for the possibility of vagueness, and borderline cases will force us to question the definition of death being used.

In any case, whichever empirical definition we choose, that empirical definition will never be able to stand as the, one and only, definition of what the word 'death' means. We might be able to say that Rosencrantz is empirically (or clinically) dead, but it will always be an open question as to whether he is dead. His soul may not have left his body, his 'anima' may not be exhausted. It is on the basis of these kinds of definition of death that we find the empirical definition acceptable, or unacceptable. The empirical definition, once formulated, can only be used to show someone is dead, if it is claimed that a human being in this biological state satisfies the non-empirical definitions. That is to say that the presence of these conditions indicates that death has occurred, where death is not here defined in biological terms. It is for this reason that I prefer the use of the word 'indicators', rather than criteria, or definitions.

If we accept Waismann's theory of language strata, a distinction can be drawn between the concept of death and the criteria for death; but only if they are treated as two different types of definition. However, it must be remembered that they are definitions of two distinct concepts, one non-empirical, the other empirical, and that these two concepts are not freely interchangeable. The terms 'empirical death', 'clinical death', or 'brainstem death' must be carefully distinguished from 'death', as a non-empirical concept. For the sake of clarity it might be better to remove the term 'brainstem death' entirely from use. While it is a convenient shorthand for 'irreversible cessation of brainstem function', it is too often viewed as being longhand for 'death', confusing the issue unnecessarily. Both Pallis and Lamb quite rightly wish to avoid such problems. Treating the criteria for death (empirical definition) as being accepted indicators of the satisfaction of some non-empirical, religious, or metaphysical, concept, cuts through these problems. At the same time, however, it makes clear that there is no necessary link between the physical state of the body and the ontological state of the human being. We could not then say that 'Rosencrantz is brainstem dead, therefore Rosencrantz is dead', or even 'brainstem death is death'. We could say 'Rosencrantz's brainstem has ceased functioning, and we accept this as indicating that he is dead', or, 'we accept that the irreversible cessation of brainstem function indicates that death has occurred'.

\section{'Organisms', materialism, 'consciousness', and moral status - problems in Lamb}

Lamb defines death as 'the irreversible loss of function of the organism as a whole' (9). His account then goes on to claim that loss of brainstem function is sufficient to 
ensure that this definition of death is satisfied, as the brainstem is the organ which integrates the organism as a whole. Again, he faces questions over the same materialist problems, as he equivocates between an empirical definition and this non-empirical definition. This definition of death also requires the assumption that a human being is merely an organism functioning in an integrated manner, which is not uncontroversial. Exactly what Lamb means by 'organism' is also unclear. By a process of elimination one could remove each organ and limb from a body, leaving only the brainstem and some interconnected peripherals for it to integrate. Lamb does not say at what point this dismemberment could be judged to have resulted in death of the organism as a whole, or death of the human being, or even death of the person.

There is no mention of capacity for consciousness in this definition, and in any case, while consciousness may be seen as one 'function' of a human being, having the capacity for consciousness is not a function at all. If Pallis is to cite Lamb, in support for his claim that brainstem death is death, some link between their nonempirical definitions of death would be helpful. Merely sharing the same demand for brainstem death as an indicator of death is not sufficient to make them philosophically compatible. Lamb's definition of death is based on a purely empirical argument, dependent on the level of technology available to us. It puts no moral value on 'consciousness', or on the life of the human being, and it does not allow for religious views. It is pure biology, where the death of a human being is the same as the death of a dog, or a frog. While this approach seems to offer the advantage of removing the emotional side of arguments about death from the discussion, I do not believe that it does in fact do so. I also do not believe that to do so would be an advantage.

What this account does is to reduce the moral status of human beings to that of dogs and frogs. It also ignores the simple fact that while many people may be interested in the welfare of animals, few are of the opinion that anything that applies to dogs equally applies to human beings. In determining what a vet can do to a dying dog we are not overly concerned with the dog's capacity for consciousness, or moral status. A vet will put a dog down with few moral qualms. One hopes that doctors have somewhat stronger feelings against killing their patients. If a dog appears to be dead, or as good as dead, then that is accepted as being good enough, for we are not particularly worried about dying dogs. When considering human beings we are worried about whether they are dead or not. Worried in a way that leads us to question the indicators of death that are being used.

Loss of the capacity for consciousness is an important factor in most definitions of death (for human beings). This importance is derived mainly from the moral status we assign to conscious beings. While Lamb recognises that our ethical ideas affect the way we treat the dead and the dying, he seems to propose that determining someone as dead is a matter of empirical biology, something that we can discover independently of our moral viewpoint. I would suggest that we cannot divorce moral and cultural influences from our interpretation of brute biological facts. The Japanese believe the soul to be located in the abdomen, and dismiss western materialist/behaviourist notions about dead brainstems equating to dead human beings. We accept brainstem dysfunction as an indicator of death because it is morally acceptable to treat the permanently irrevocably unconscious as dead, not because it is good biology. Indeed it may not be good biology at all: even if the brainstem death test shows that the capacity for consciousness has gone, which is debatable (4), neither Lamb nor Pallis give a justification for using apnoea as one of their criteria. Both also owe us an account of what they each mean by consciousness, and an account of their presumably materialist backing for such a definition of consciousness. Lamb also needs an account of human beings as organisms, and what, if any, moral status mere organisms have.

\section{The DCE - a better 'definition' of 'death'?}

If we examine the proposals put forward by Rix, we find that ' $(i)$ a person should be declared dead only when all brain, heart and lung function has ceased' (1). It should be noted that this 'formulation' is not as 'slipshod' as Pallis claims (5). For the sake of certainty, and to block any chance of petty arguments arising over the status of someone with a reversible cardiac arrest, it would be better to stipulate irreversible cessation of the three functions. However, this 'formulation' is not at fault in the way that Pallis and Lamb seem to think. It does not specify that cessation of heart function is the, one and only, criterion for death. It demands the absence of all three functions. The loss of only one of these functions is not sufficient for death. Nor does this formulation leave us in any doubts as to the ontological status of a transplant donor and the patient who now has 'the donor's heart'. Function, not the provenance of an individual organ, is important here. The man with the artificial heart is no more dead for the Danes than he is for anyone else. It should also be noted that this formulation stipulates 'all brain functions', not just brainstem function, which should answer any fears about patients who are 'locked in'.

Moreover, Raanan Gillon's comment in the editorial (10), (that if a human person is the unity of consciousness and body, and the capacity for consciousness has ceased to exist, then the human person has ceased to exist), does not bear as much weight as it seems. We are not concerned with the existence of persons here, although that is a very important concern. We are concerned with life and death. If a human being is only dead when all three functions specified above have ceased, then, by parallel reasoning to that used by Gillon, he or she is not dead until that has happened. They may have ceased to be 
persons, they may be beyond help and doomed to die, but they are not yet dead. For Gillon's argument to bear weight in this context, we must accept that death is equivalent to the cessation of the existence of the person. It is however, quite acceptable to talk of dead persons without meaning that the person has ceased to exist. To say 'My grandfather is dead' refers quite clearly to a person, but does not commit me to a belief that he does not exist. I may be a dualist, or I may still refer to his body as being my grandfather. Life and death, especially in theology, are often terms used to denote modes of existence.

When considering heart and lung function of course, we are aware that medical technology can replace, or assist, defective organs. The same is not yet true of the brain. This, I believe, is the reason behind Rix's second point, that '(ii) with the cessation of brain function the person has entered the death process' (1). He could easily have said that the 'death process' has been entered when either heart or lung function has irreversibly ceased. The idea of death as a process might seem difficult for us to accept: death is usually viewed as being an event or a state. However, dying may be considered to be a process, whether it takes years, days, or only hours. In a trivially true sense we are all dying, since our life ends with death, but here we are concerned with that stage of the process of dying that immediately precedes death: the stage where death is inevitable. 'The death process' is a technical term, which may be rendered as 'beyond medical help', or 'irremediably dying' (11). Dying is not an irreversible process, until that process gets to a point where our available technology cannot help. At our current level of technology, that point is reached when the heart ceases to function and we can do nothing to replace it, or restart it, before respiration and brain function cease. It can be reached when respiration ceases to be effective, no matter what medical techniques are tried, and anoxia completes the process. Alternatively, it may be the point at which the brain ceases to function, whether or not the patient is on a ventilator. Once the patient is beyond any help, death is inevitable.

In most cases, as Pallis stresses, it is the cessation of either cardiac or respiratory function that leads to death. Rosencrantz, without access to an intensive care unit (ICU), is dying when his heart stops, even if he can gasp a few breaths and his brainstem continues to function for a few minutes more. To be consistent Pallis would have to delay the declaration of Rosencrantz's death until we could be sure that his brainstem had ceased functioning. So would Rix, for only then would the 'death process' be complete. Guildenstern, within an ICU, has a similar cardiac arrest. If he is given the correct treatment, he may be dragged back from the brink of death. Yet it seems obvious that Guildenstern is indeed dying, which is why such heroic efforts are made to save him. If those efforts fail Guildenstern will be dead, but, while for
Pallis that cardiac arrest may be seen as the cause of death, for Rix it has a different significance. It is the start of the 'death process', despite the fact that it is unknown whether or not that function has, in fact, irreversibly ceased, until steps to reverse that cessation have been tried and have failed.

In most cases of brainstem death the cessation of cardiac and respiratory function follows within a similar short period of time. It is only when a patient is on life-support machinery, that the cessation of brain function is not immediately followed by cessation of respiratory and cardiac activity. Thus Rix, who is only considering this type of situation, stipulates that '(iii) the death process should not be prolonged after brain function has ceased' (1). Only in this situation, is it worth stipulating that the 'death process' should not be prolonged, for this is the only situation where the inevitable process of dying can be prolonged. This is not to say that the patient is already dead. According to this view of death, no matter which function ceases first, the patient is still alive until the other two functions have ceased. Rix makes this clear by saying that ' $(i v)$ the time of death is given by the end, not by the beginning of the death process' (1).

This account of death, in terms of these three indicators, jointly employed, is clear, precise, and practical. It does not require the clinician to use any unusual, or untried, techniques of diagnosis. Using these indicators for death is no more problematic than using the current UK set of indicators; all these conditions may be assessed at the bedside, each is clearly diagnosable. For legal purposes the time of death can be established with as much precision as we can expect from the use of 'brainstem death only' as our death criterion. It appears to me that, on legal and medical grounds there can be little objection to using this definition and using these guidelines. The morale of nursing staff need not be affected, and the expense of keeping brain-dead patients on respirators need not be incurred. On ethical grounds it may be argued that, once a patient has entered the 'death process', he is, by definition, beyond help, and treatment can be withdrawn.

If we compare this account of death with the 'criteria' favoured by Lamb and Pallis, we find that both can fulfil legal requirements for a time of death. Both are medically diagnosable, and are precise in the way that medicine requires. The main objections to using 'brainstem death only' as the criterion for death are that it is not acceptable to a large number of people on religious grounds, and that it is not acceptable to many doctors, on medical grounds. The set of indicators proposed by the DCE meets most of these objections. In addition it should be noted that, if a definition of death must stand on the merits of its philosophical backing and its ease of use in practice, then, at the very least, the claim that 'brainstem death is death' is propped up on no better supports than those that could be offered for a Rixian definition. 


\section{'Moral status', 'death' and 'organ harvesting' - inter-relationships?}

The attribution of moral status to a human being is important when considering how we should treat the dead and dying. As patients approach death, their moral status changes. Death-bed testimony, last words and last wishes have a strong impact; we feel obliged to treat them with respect. At the same time we do not necessarily feel obliged to tell the dying patient the truth, and the convention of patient/doctor confidentiality may be set aside. On entering the final stage of dying, the 'death process', I would argue that the moral status of the patient will have changed again.

As Alexander Morgan Capron states 'the debate about putting "hopeless" comatose patients through "gruesome" treatment is important in its own right.' (12), but I am not sure that it is, as he claims, a separate issue. When the patient has entered the 'death process', not only is it then hopeless to continue treatment, including ventilation, but it may be acceptable to consider organ harvesting. Discussions of the method for determining death may be distinguished from discussions of the ethics of transplant surgery, or the ethics of withdrawing treatment, but it may not be possible to divorce them totally from each other in the way that Lamb might wish (13). The chief justification for organ harvesting has been, to date, that the donor is dead, and that it is morally acceptable to take organs from the dead. The chief objection is that they are not $\mathrm{dead}$, and that it is therefore unacceptable. If we agree that it is acceptable to harvest organs from the dead, then to say Rosencrantz is (or is not) dead, in this context, is also to say that it is (or is not) now morally acceptable to remove organs from his body. It is a statement with implications not just about the physiological status of the body, but also about the moral status of the person. Using the definition of death proposed by Rix and the DCE does not pose any new problems for those who already favour organ harvesting from brainstem dead patients.

Guildenstern, a prospective donor, is declared to have entered the Rixian 'death process' when it is found that his brain has ceased to function. He is not dead, but he is in physiologically the same state as those who are currently declared dead under the UK guidelines. If the consensus of public opinion is that someone in that state is a suitable candidate for organ removal, then it does not matter much whether he is termed 'dead', or 'irremediably dying'. His moral status is such that organ retrieval is permissible. Organ retrieval would constitute the 'proximate cause' of death, by ending the 'death process', but it would not be the ultimate, primary, or secondary cause of death. Legally, and I believe morally, the cause of death could be seen as that event which had caused the patient to enter the 'death process'. It seems unreasonable to speak of removing the heart as killing the patient, since leaving the heart in place also results in his death. Removing the organ or leaving it in place are morally on all fours.

While the application of a Rixian approach may at first cause some public concern, a well-informed public would soon come to accept that its concerns are groundless. Those who would not accept such a proposal, on the grounds that the human being is not dead, would be exactly the same people who currently do not accept the 'definition of death' favoured by Pallis and Lamb. The great advantage of conceding that brainstem death is not necessarily 'death', would be that the arguments over the definition of death could finally be put aside, or left to the theologians and philosophers. The real issues of what can be done to whom, and when, the withdrawal of treatment and the ethics of transplant surgery could then be discussed, without fear of accusations about vested interests and intellectual dishonesty.

\section{Acknowledgements}

I should like to acknowledge the continuing support of the Department of Education for Northern Ireland, which is currently funding my postgraduate research, and to thank Messrs C McKnight, D Rashid, and M Stchedroff of the Department of Philosophy, The Queen's University, Belfast (QUB), for their help in the preparation of this article. I should also like to thank the following for their helpful comments, and criticism of my views which they do not necessary endorse: Professor W F M Wallace (Applied Physiology, QUB); Mr D P Byrnes (Clinical Senior Lecturer, QUB and Neuro-surgery Department, Royal Victoria Hospital, Belfast); Mr H J P Fee (Senior Lecturer in Anaesthetics, QUB).

Fohn $F$ Catherwood, $M A$, is a doctoral research student in the Department of Philosophy, The Queen's University, Belfast.

\section{References and notes}

(1) Rix B A. Danish ethics council rejects brain death as the criterion of death. Fournal of medical ethics 1990; 16: 5-7.

(2) Lamb D. Wanting it both ways. Fournal of medical ethics 1990; 16: 8-9 and Pallis C. Return to Elsinore. Fournal of medical ethics 1990; 16: 10-13.

(3) Pallis C. ABC of brainstem death. London: British medical journal 1983.

(4) Evans D W, Hill D J. The brainstems of organ donors are not dead. Catholic medical quarterly 1989; XL, 3 (243): 113-121.

(5) See reference (2): Pallis C.

(6) Waismann F. Language strata. Synthese 1946; v: 211219.

(7) This particularly applies to eliminative materialism, but even a non-eliminative materialism shares some of these difficulties.

(8) I simply wish to point out that there is no entailment here. I do not wish to deny the possibility of there being some connection, but if the notions of entailment or causal connection are being used they require some elucidation.

(9) Lamb D. Brain death and brainstem death: 
philosophical and ethical considerations. In: Evans J D G, ed. Moral philosophy and contemporary problems. Royal Institute of Philosophy Series. Cambridge: Cambridge University Press, 1988.

(10) Gillon R [editorial]. Death. Fournal of medical ethics $1990 ; 16: 3-4$.

(11) Note: 'irremediably' rather than 'irreversibly'. This account is concerned with the state of the patient in relation to available technology. I do not wish to introduce empirically suspect notions such as irreversibility.

(12) Capron A M. Criteria of death. Fournal of medical ethics 1990; 16: 167

(13) See reference (2): Lamb D. 